\title{
On exhibiting reptiles
}

\author{
CARL GANS
}

Professor of Zoology, Division of Biological Sciences, The University of Michigan, Ann Arbor, Michigan 48109, USA

Herpetology may not be the biological discipline of highest esteem in the public view but, among zoo animals, reptiles clearly rank near the top in their attractiveness. The snake that lost its limbs after misleading Eve, the asp that permitted Cleopatra to terminate her spectacular career, the house snake of Greek mythology, and Sherlock Holmes' speckled band all manifest the intrinsic fascination and aura of danger accompanying modern snakes. The fascination of other reptiles is different but as profound as that of snakes. The iguana, skink and crocodile share affinities with the dragon, and the shell of the tortoise reminds students of Hindu and other eastern mythology that a large turtle supports the foundations of the earth. Perhaps the scaly skin and 'cold blood' induce curiosity, whereas the fear of venom, the odd shape and the curious behaviour increase the interest.

The intrinsic attractiveness of reptiles as exhibit animals is clear. Most zoos capitalise upon this, and the present volume contains a collection of reports dealing with some by-products of such exhibit programmes. It seems useful, as part of its introduction, to consider some, more general aspects regarding the philosophy and requirements of reptilian exhibition, about the place of zoos in the conservation scheme, about reptilian adaptations, and about the place of research or organised discovery in an exhibit park. Although opposing views are alluded to, what follows is primarily a personal statement, based upon some decades of interaction with the various amateur and professional publics faced by a herpetologist, and presumably tinted quite strongly by the biases of a long-time afficionado of reptiles.

\section{EXHIBITION AND CONSERVATION}

The German behaviourist von Uxküll coined the term 'Umwelt', meaning the conceptual world of organisms. It is often forgotten that he also applied this term to different cultural groups of people. He presumably implied that the human Umwelt incorporated the potential for change. The pace of events in every-day life makes us forget that we live at a moment in history during which the Umwelt of herpetologists has changed explosively.

In part, this change has been due to the rapid shift in our physical surroundings. A few decades ago, we lived on islands of man-made environment, forming larger or smaller patches amid remnants of the original biota. Large forests had been destroyed, but smaller woodlands of slightly different species composition had often taken their place. Many areas had been lost to monoculture, but ravines and hillsides, parks and marshes generally retained aspects of the original vegetation. Bison and wolf, aurochs and puma, passenger pigeon and Carolina parakeet might have been severely restricted or exterminated, but most smaller animals remained, with the possible exception of those that were tied very closely to high-forest or other specialised biotopes.

All this has changed. Human-population density has continued to increase explosively and, with it, there has been a shift in the pattern of land utilisation. From islands of habitations in a more or less disturbed environment, we have shifted to shrinking islands of natural vegetation, surrounded by asphalt and cement. Roads, that once were winding, four-metre strips of compacted or black-topped soil, are now 40-metre bands of concrete with curves and cement barriers; even their berms are trimmed. Ponds have been drained and their edges cemented. Swamps and marshlands have been filled and rivers straightened. Even though this manicuring of our environment has drastically reduced its diversity, it has been the lesser of the problems with which we have faced the biota. More critical has been the plethora of chemical compounds released into the environment. Detergents and insecticides, automobile emissions and herbicides are deleterious. They often kill on contact and accumulate in the food chain. However, the greatest threat is presented when they are spread across the landscape, both within organisms and in 
smokes and aerosols; even areas never sprayed or occupied are now affected.

The results have been extinction or reduction in the number of individuals, increases in individual abnormalities and changes in species composition of communities. Unfortunately, most such statements have to be based upon indirect evidence. We did not know enough when the alteration started, nor do we know enough yet to have baseline data for most populations, to be certain of the rates of change, to know the magnitude and permanence of the effects.

A by-product of the widespread environmental destruction has been the exponential increase in public awareness that an environmental degradation might indeed be occurring; primarily through the medium of television, the average citizen has also, and for the first time, achieved a concept of animal beauty and diversity. In parallel, has come a revolution in public consciousness. It suddenly became respectable, even fashionable, to ask questions about all kinds of animal utilisation and treatment. Legal controls are no longer applied exclusively to exploitative hunting and to the skin trade. Even when the collection of animals does not affect the status of the wild populations, one now encounters questions about the ethics of removing any individual from the wild, about subjecting animals to study, using their products, keeping them as pets, and exhibiting them in zoos.

Many such questions, of course, seem ridiculous to us, although not to the questioners; we must, nevertheless, be prepared to deal with them. Many popular sources of information present a somcwhat biased view and most certainly a simplistic one, that inevitably communicates only a partial story. They generally stress entertainment at the expense of information. Films showing animal behaviour are often manicured into a format that eliminates any observation which might suggest that pain and killing are also aspects of the natural world. Still, administrators, curators, and keepers of organisms (as well as researchers and parks managers) face questions about the justification of their activities. It is necessary for us to be able to respond intelligently, not just to defend our practices but presumably because of a personal commitment to the longrange survival of the organisms that we exhibit.
This, then, raises the question of why we keep animals in cages and why we exhibit them. What is the justification for taking some dozens or hundreds of gaboon vipers from the jungles of West Africa, monitors from the paddy fields of India, iguanas from the river forests of South America so that we can maintain the very few survivors on artificial diets in an artificial environment?

One occasionally hears arguments that zoos can be sites for captive breeding. However, while this has been the case for the Pere David deer, the wisent and a few species of birds, it can only be applied to truly special cases, generally involving large and spectacular organisms. The breeding population for each such species has to be maintained large enough to save a significant fraction of its gene pool. Studbooks and complex records have to be maintained to limit inbreeding and to reduce artificial selection. There are cases of record in which species of reptiles and amphibians have been bred in captivity, but relatively few in which this pattern has been continued for more than one, two or three generations. Even if the number of species involved in captive breeding were to increase a hundred-or thousandfold, it is unlikely that we will achieve more than the replenishment of the stocks to be maintained in other zoos; consequently, exhibition is likely to continue to represent a net drain on wild populations.

Another justification is one of entertainment. Animals are intrinsically attractive. Petting animals is fun and may even scratch some deep urge in many of us. Animal rides are almost as enjoyable as merry-go-rounds and roller coasters. Walks through nicely landscaped gardens, which are interspersed among 'oh my' exhibits showing giraffes, elephants and giant snakes, may be pleasant and relaxing, and may engender a good feeling about the animals one meets in these surroundings. Entertainment may ultimately be one of the major attractions of zoos; certainly it is demanded and supported by the public. However, the use of animals in entertainment is intrinsically exploitative, whether it occurs in a zoo or a circus. The use of animals as entertainment alone is different, but no 'better' or 'worse' than the use of their flesh as food or their skins for clothing or shelter. Zoos need to be better than stationary circuses. 
It is perhaps most justifiable to defend the existence of living exhibits as educational devices. This does not mean that the public needs to 'matriculate' on passing through the entry turnstile, or that it needs to be able to pass an examination before receiving a 'diploma' before the egress. Rather, zoos should be able to provide educational reinforcement and furnish the details for a series of statements such as: 'Animals are diverse.' 'Animals are also beautiful.' 'Some of this beauty is inherent in their complex adaptations to particular environments.' 'Their beauty makes it desirable to work toward their continued existence on this planet.' 'Their continued existence is important enough to justify the expenditure of limiting resources, such as land that might otherwise produce minerals, food, or timber.' For this set of messages, zoos may be even better than motion pictures and the television screen in every home. The impressiveness of 'real' animals cannot be overestimated. Sealion and rhino, penguin and ostrich, cobra and caiman, beetle and sea anemone; they all offer unique perspectives to the viewer. These perspectives are particularly critical for the ever-increasing fraction of visitors that will never have a chance to see any exotic animal in the wild. The single, most important function of zoos may then be that of convincing the public of these general items and of providing multiple documentation thereof.

There are, of course, further and more formal aspects of education. Biology and its subdisciplines of zoology, behaviour, morphology and physiology require a look at and an appreciation for living animals. Whether the teaching proceeds in public school, high school or college, the animals in the local zoo represent an important resource, one that is often inadequately presented and insufficiently utilised. This is a complex story to which we can only allude. However, a successful use of the zoo cannot proceed from a one-time, unprepared tour any more than a teacher can present an excellent lecture without prior consideration of the topic. Planning and selection, both in the exhibition and the utilisation scheme, are obviously critical aspects that will determine success or failure of the educational effort.

Although exhibits may be justified on a number of grounds, there is also a further responsibility to the organisms. It must be recognised that living specimens exhibited in a zoo and preserved specimens that once were exhibited in a zoo may continue to contribute to our understanding of the biology of the form. Sometimes, they may provide information that has previously been unavailable. It is essential that such material be collected systematically and made available to other interested students, whether they be employed in zoos or national parks, in universities or museums. Those zoos, which have as their charter the advancement of appreciation and knowledge of animal diversity, must actively encourage the extraction of maximal information from each specimen or rather each captive breeding population.

All of the items and those to follow imply that the keepers and curators in charge of the animals be professionals. They should know about the biology of their charges; they should know what research is being done elsewhere on these and similar organisms; they should be able to apply the resules and assure that their charges remain healthy and comfortable. Keepers should not be janitors. Some level of biological training might be a minimum requirement and there should be the opportunity for participation in refresher courses and encouragement for advanced training where possible. The well being of organisms does not proceed automatically by dropping them into nicely landscaped cages; it requires the personal commitment of a professional staff.

\section{EXHIBITION AND EDUCATION}

The average reptile house may provide the visitor with cold shivers or a momentary excitement; however, it communicates neither what reptiles are nor how they differ from other vertebrates. This is sadly true in spite of many progressive modifications and the inclusion of vatious kinds of amplified labels. I would here like to suggest that it may well be appropriate for reptile houses to communicate the general concept of adaptation and, more specifically, to note how reptiles differ from fishes and amphibians and again from birds and mammals. Also of interest might be some of the specialisations in which they differ among each other.

Before we can decide how best to exhibit reptilian adaptations, we must have some concept 
of their nature. How then, should we characterise these animals? What would a specialist consider their most significant adaptation? How do the various adaptations differ among the several reptilian groups? Only after we have clarified the answers to such questions can we decide which aspects of reptiles are important to the several publics of a zoological park and how these aspects may best be communicated.

Let us consider the definition of reptiles as an example. That reptiles belong among the vertebrates presumably needs only the briefest mention; after all, they have backbones and so do almost all creatures exhibited in the average zoo. More specifically, reptiles may be defined as the only ectothermal amniotes; however, this textbook characterisation involves a sequence of concepts that is far from simple (cf. Gans \& Dawson, 1976).

The term ectotherm implies that reptiles maintain their mean body temperature by shuttling from external heat source to external heat sink. After all, the vast majority of reptiles cannot maintain an elevated body temperature for significant periods by raising their metabolic rate. In this aspect, reptiles differ from birds and mammals, which do modify their metabolic rate, and are more like amphibians and fishes which cannot do so. The idea of ectothermy does imply that reptiles have some central receptor system that allows them to determine temperature levels, though there is an active argument as to whether they control for a mean temperature some place within the preferred range or whether they use temperature receptors to determine maxima, minima or other descriptors.

The term amniote means that reptiles can produce amniotic eggs, a specialisation that joins reptiles to mammals and birds and distinguishes them from fishes and amphibians. The early cell divisions of an amniotic egg result in the formation of multiple membranes, one of which, the amnion, surrounds what will later become the embryo, permitting it to grow in a pool of amniotic fluid. Other membranes represent evaginations of the primary gut (and enclose the yolk) and of the cloacal region (and enclose the waste products of the kidney). By providing the embryo with its own pool of liquid, the reptiles are thus freed from having to deposit their eggs in truly aquatic situations. Such amniotic eggs tend to be shelled, presumably reducing evaporation from the overall egg mass and also deterring predators. Consequently, fertilisation has to occur before the shell is deposited and must be internal.

Unfortunately the simple statement 'ectothermal amniotes' hides the contrasting complexity, replete with exceptions. Let us first examine the term endothermy and its associated concept of temperature control. A few snakes, and perhaps some other reptiles, are not just ectotherms, but manage to raise their body temperature by regular convulsive muscular contractions. The temperature rise, induced by this extra effort, allows a female python to maintain her eggs at an elevated temperature. In contrast, certain mammals, such as bats, do not keep their body temperature constant, but permit it to drop (by decreasing heat production) at night and during aestivation. This reduces the amount of energy they then have to expend and, of course, limits the food consumption needed to maintain them.

Looking at the word 'amniotes', the second term of the definition, one encounters further complexities. One curious aspect is that certain reptiles retain fertilised eggs for varying periods, in some cases until term; the embryo then remains within the female until hours before hatching. In other species, no shell is deposited around the egg. One thus encounters multiple kinds of viviparity (=live birth). Formerly, the extreme was referred to as ovoviviparity; but we now know of many intermediate conditions, which range from a true placenta, through which nutrients are provided and waste products removed from the developing embryo, to a condition in which the egg is sheltered in the oviduct of the female, but receives only minimal nutrition (Fox, 1977; Tinkle \& Gibbons, 1977). The extremes of the spectrum of conditions seen in reptiles presage the diversity expressed by birds and mammals. The former endow the young with a mass of yolk, packaged within the shell together with the embryo, and almost all the latter (the monotremes being an exception) provide the ovum with only minimal yolk and nourish the developing embryo via placentation, by lactation, or by both.

Thus far, we have discussed the rextbook approach to the definition of reptiles. However, recent studies suggest multiple further levels of complexity involved in these systems. It may be 
useful to consider thermal and metabolic relations, as these may well be among the more critical adaptations of reptiles. To approach these issues, we should not ask how reptiles function in the laboratory or zoo, but must inquire what might be the biological role or, in more popular terms, what is the long-range advantage of the particular suite of adaptations that we have been describing. It is critical that we remember that reptiles do not operate as 'imperfect' endotherms, always striving toward the maintenance of a high body temperature and the conspicuous consumption of energy, characteristic of mammals and birds.

The maintenance of constant body temperatures provides an excellent example of such complexity. Ever since the interesting studies of Bogert \& Cowles during the early 1940's, we have known that many reptiles do not allow their temperature to swing randomly, at the vagary of the environment. Rather, they attempt to maintain thermal preferenda, or eccritic temperatures; thus, lizards bask in the morning and give up heat underground to tunnel walls at midday. We have numerous observations and elegant mechanistic schemes showing that lizards orient their body, change their pigmentation and otherwise modify their appearance and behaviour in order to maintain these levels. The hormonal systems of many reptiles do not seem to function below $26^{\circ} \mathrm{C}$. Furthermore, the thermal reaction optima of reptilian enzyme systems, hearing curves, and other physiological processes are matched to these thermal preferenda. Lizards may even change their behaviour when cool, as their body then performs more slowly (Rand, 1964).

We have long known, but until recently ignored, other observations which document that reptiles do not operate continuously near 'optimum' temperature, but often depart from a strictly mechanistic thermal regime. It seems obvious that a lizard would tolerate some change from the thermal optimum in order to obtain food or find a mate. More recently, we have encountered forest-dwelling species of lizards, some members of which never reach their thermal optimum. Those populations living in dense forest apparently operate continuously at shade temperatures, whereas other species occupying the edges of the forest thermoregulate to a higher temperature level by shuttling back and forth into the sunshine. It becomes clear that such animals are balancing the energetic benefits of an elevated body temperature against the risks associated with the shuttling behaviour. Travel obviously costs energy and exposes one to enemies; if source and sink are too far separated, it may be more economical to avoid switching (Huey \& Slatkın, 1976).

Reptiles are hardly automatons that slavishly obey a series of absolute thermal commands. Rather, reptiles show a pattern by which diverse species utilise the levels of thermal energy normal to their particular environment. Their eccritic temperature generally reflects the thermal level of their surroundings and their physiological properties show temperature optima that do not involve excessive cost to the species. Some desert reptiles tend to operate at eccritic temperatures equivalent to or exceeding the body temperatures of mammals of equivalent size, while the eccritic temperatures of reptiles of temperate zones are very substantially lower.

A much more significant corollary of the thermal situation relates to the basal metabolic rate. The difference between ectotherms and endotherms is not restricted to the mechanism of heat acquisition; rather, endotherms demonstrate a six- to ten-fold higher weight-specific basal metabolic rate than that of ectotherms at the same temperature. This permits a completely different strategy from that demonstrated by birds and mammals and allows populations of reptiles to occupy environments that may lack sufficient nutrients to support equivalent populations of mammals. The effect is enhanced, because the metabolic scope or range over which the metabolic rate may be shifted from rest to maximum sustained activity is a function of the basal metabolic rate. This makes it critical, when comparing the energy budgets of ectotherms and endotherms, to include the fraction of the total time that each individual will rest or be active. Field studies now suggest that reptiles apparently move about only one-third as much as do mammals (Bennett \& Nagy, 1977). At least for some reptilian populations, the food required for maintenance is one-thirtieth that required by an equal number of mammals of the same weight. If there were a minimum number of individuals that would allow a species to survive in a given area, it would only require one-thirtieth the food resources to maintain a population of reptiles 
than it would to maintain an equivalent population of mammals of the same size. Presumably mammals could only have adopted such an energetic pattern after they had developed a most effective food-procurement system; however, it has been suggested that ectothermy may well involve specialisations that would let reptiles survive in marginal habitats.

How can one communicate such sets of ideas to the public? There is, of course, no reason why a simplified and diagrammed version of many aspects of these stories could not be transmitted as part of labels and graphics. Amniotic eggs lend themselves to excellent three-dimensional models. The development of placentation can be shown by contrasting eggs with living young or, better yet, by utilising the occasional opportunity for showing a female snake with newborn young or a python incubating eggs. Where funds are available, closed-circuit television may increase the image size and protect the incubating reptile from disturbance. Projection of short film sequences, via rear-view screens, can remind the viewer of other variants of the scene, such as marine turtles migrating onto shore, or female crocodiles carrying their emerging young to water (cf. Gans \& Van den Sande, 1976, for examples of exhibition techniques).

The temperature story lends itself to even more innovative approaches. It is easy to show that reptiles will maintain their temperature by moving to appropriate sources and sinks of heat when the local temperatures within a cage are shifted. Telemetry and temperature print-outs represent an obvious approach; however, it would be simpler and cheaper to glue small dial thermometers to a few rocks and to the shell of some turtles and let the public discover the fact of temperature constancy for themselves. Lizards have been conditioned to turn heat lamps on and off, and crocodilians will move to warm water when the air temperature drops. The opportunities for instructive exhibits seem endless. Exposure to such exhibits is likely to yield some level of understanding, assuming the mechanism is appropriately explained before, during, and after the visitor meets it. Quite similar approaches can also be applied to topics of feeding and migration, to sexual display and mating and, in short, to any of the adaptations of reptiles. In each case, we can see an increase in the attractive- ness of the exhibit and an increase in the basic justification for exhibiting these animals in the first place.

\section{EXHIBITION AND RESEARCH}

It should hardly be necessary to provide a justification for research in this volume, as it is, after all, dedicated to the promulgation of new discoveries. Yet, even though some zoological parks and their parent societies have made spectacular contributions to our understanding of animals, relatively few zoos have formal research programmes or encourage their staff to engage in systematic investigation. Conscquently, there may be some justification for offering a more detailed rationale in support of the organised observation of organisms, and the publication of the results of such study.

Let me begin by noting what is implied by research under the present circumstances. In simplest terms, it means carrying out systematic observations and perhaps simple tests on the organisms. Secondly, it involves evaluations of these observations to test whether they indeed represent some kind of a general phenomenon, or only isolated historical incidents that would not have predictive value for future occurrences. Finally, after testing that the results are indeed new and significant, it means publication of the results. Others may then have a chance to learn from the report or, better yet, will have a chance to test the results by further observations. All three of these phases are important if the enterprise is to have real benefit to all concerned, including the animals.

Observations may initially be triggered by incidental notice of a phenomenon, such as the start of egg deposition by a rare species, an unusual feeding habit, or the peculiar colour patterns on a newly arrived specimen. One must then make a decision whether the topic is worthy of further study. If the decision is positive, the observations should be carried out in that format most likely to lead to repeatable results. As this is not a treatise on the scientific method, I will only refer to the concept of controls in observation as well as in experiment. I do want to stress that the first and second stages of investigation are inexorably intertwined. Decisions are necessary. How can we test what has been done before? How can we supplement it? Both are as impor- 
tant as a different decision, namely, which of the many things observed every day should be pursued, because they are likely to lead to interesting and useful results. It is clearly impossible for a kecper or a curator to make simultaneous observations on each of the hundred or more species being exhibited.

The need for publication of the results of investigation cannot be stressed too much. It is, of course, intellectually satisfying to discover something new and to know things as yet undiscovered by others. However, this must only be the first stage of any project. If the investigative process is to increase the long-range well being of the organism, it requires more than the attitude of 'I discovered this years ago', that one occasionally encounters. Refusal to publish causes others to repeat the observations and experiments. Thus, each generation may have to rediscover the wheel, and some generations will not have an opportunity to make these discoveries, to the detriment of the animals with which we are dealing.

Much more important is that publication inevitably subjects ideas to test by exposing them to the evaluation and commentary of others. This process can be traumatic, and the trauma accounts for the unwillingness of some discoverers to become authors. However, there are advantages to publishing in a refereed journal rather than an unrefereed and often unedited newsletter or house organ. A good editor and a responsible set of referees can provide the author with a preview of audience response and are often able to advise regarding additional work to be done, additional literature to be referred to, and the pattern in which a particular set of information can be most effectively communicated. Certainly the process of investigation, evaluation and publication must involve communication. There had best be a collaborative enterprise, a modern version of mediaeval apprenticeship, among all those who deal with reptiles and amphibians. Conversation, correspondence and, ultimately, published exchange of information among those interested in zoology and herpetology, whether employed by national parks, museums, universities, zoos or industry, obviously increases the rate at which all learn, and the rate at which the common body of knowledge is increased and refined.
The fundamental reason for study is again one of ethics. If we wish to exhibit exotic animals for any of the reasons discussed above, their exhibition should proceed with the least discomfort to them. This suggests that we be able to recognise the optimum, or at least the acceptable, conditions demanded by the particular species, as well as those aspects of the environment important for the maintenance of the form. Practical questions, that immediately come to mind, relate to the absolute size and dimensions of cages, the humidity and temperature levels therein, the possibility of cycling physical parameters, the likelihood for interaction among individuals of the same species, and the advantages and limitations of exhibiting the particular species alone or in mixed groups. Unfortunately, much of what has been published on these subjects incorporates more folklore than science.

Although such general projects may be the obvious ones for, after all, they will provide immediate answers to problems faced by zoos, they are probably the least useful for a first-level project, because they are likely to be the most difficult ones on which to obtain unequivocal solutions. The reason is that those conditions suitable for one reptile may not pertain to many others, and many of the parameters described have to be determined independently for each group of species; average values will be suitable for only a few reptiles.

Furthermore, the utility of any one parameter, for instance the use of lamps containing one or another wavelength of UV light, should presumably be tested against a population of specimens; relatively few zoos will have the 20 or so specimens of a particular species on which to perform controlled tests. For that matter, the criteria of success demand a long-range rather than a shortrange evaluation. One-time captive reproduction of a species, that reproduces annually or biennally in the wild, is only the first indicator that something may be going right. Only when the offspring themselves successfully reproduce in captivity may one assume that captive propagation seems to be successful.

Unfortunately, our knowledge of most wild animals is still extremely scanty. This does mean that there are enormous numbers of important projects that must still be done, that meet the criteria of providing new information and that 
are particularly well suited to seudy in zoos. Under this heading come the many aspects of animal behaviour and ethology, characterising the responses of animals to members of the same and other species (Carpenter, I978). Also included here are multiple observations on the kinds of food taken, and the way food is ingested and digested. This kind of study could well do with a bit more imagination, utilising some of the literature on reptilian learning (Burghardt, 1978); to understand the meaning of decisions by an animal, one has to offer a choice of food types, utilising more nearly controlled experiments. Then, there is the problem of social interaction prior to reproduction, both among males and females, between members of mating pairs, and toward the newborn and growing young. Even though it is known that the behaviour of many species changes as they grow and age, this has been unequivocably characterised only for a few forms. Many aspects would seem to remain in need of investigation.

Another kind of research involves biochemical and cytological evaluation, as well as comparative pathology and medicine. Much information may be gained from examination of tissue biopsies, and from blood, saliva and urine sampling. Questions about reptilian karyotypes, metabolic by-products, haematocrit, and other parameters may arise as the by-product of studies by scientists in other institutions. It is often possible to answer these questions by sampling many individual reptiles, that may be housed in multiple collections. Such work may generally be carried out without exposing any individual reptile to harm. It is good to report that many requests for such assistance appear now to be supported, even though such investigations are apt to be longrange and extensive and to provide the least personal recognition to those staff members who have to assist in the procedures.

Zoos also have to face the fact that the utility of their charges does not end when the specimen dies. In some countries, the procedure for ultimate disposal of the specimen has already been written into law; for instance the United States Endangered Species Act requires that specimens of endangered or threatened species shall be deposited in appropriate scientific collections after their first use has been met. Deposit in a museum or other research collection allows other workers to refer to and utilise the specimens at a later stage, and limits the drain on wildlife populations.

Deposit of specimens in a museum also should be the rule rather than the exception for all specimens that have provided publishable results. While we may assume that the specimen was correctly identified in the first place, our taxonomic certitude has recently encountered shocks. Cryptic species have been uncovered which differ primarily by the pattern of the mating call, in chromosome arrangement, or some other aspect obscure to us. Only after we know about these, may we be able to sort specimens on the basis of more subtle, but externally visible, characteristics. If specimens have been deposited in a collection (and the site of deposit has been recorded in the initial report), it will be possible to confirm their identification. However, when the specimens are mixed with others or die, rot and are discarded, the project may have to be repeated. Hence, identification and deposit should be the rule for specimens of rare species or from poorly known regions. Such a rule imposes additional work on the curatorial staff. Individual specimens have to be marked and accurate records must be kept, for instance of the locality and date of collection of each specimen. Specimens furthermore have to be watched so that they will not die and decay in a corner of the cage. Preservation must be rapid and designed to retain the utility of the specimen. The rule also requires the co-operation of an accredited collection; however, it is another way by which we can assure that every specimen removed from the wild contributes to the overall benefit.

This kind of consideration also applies to two other aspects that are often unconnected. The first is the handling of post-mortem examinations, and the second the handling of animals born or hatched in zoos.

The first problem arises when an animal dies. The presumed cause of death obviously has to be sought out, primarily from the viewpoint that such deaths are best avoided in other captive individuals. Thus, autopsies may have to be carried out, in order to identify the cause of death and to derive decisions that will allow the attending veterinarian to improve treatment in future cases. However, pathological examination inevitably involves some damage to the specimen. If it is very thorough, it may render the individual 
useless for subsequent morphometric or anatomical study; too often specimens are turned into conditions that raises questions about their future identification. This means that a value judgment must be made regarding the extent to which autopsy is to proceed. It also means that patterns of skinning and opening of the visceral cavity might take the needs of subsequent investigators into account. For instance, unilateral, rather than medial, incisions permit subsequent study of skeleton and muscles on the unoperated side. Tissue samples might be frozen for biochemical assay, rather than having the entire animal dunked into preservative. Once the cause of death has been established, the pathologist's further interest in the inside of a diseased reptile should be balanced against the interest of other investigators. All such concerns should be balanced against the probability that the activities will result in a report publishable in an appropriate scientific journal.

The colour patterns, proportions and structural arrangements of hatchling lizards, snakes, or turtles may be drastically different from those of adults. One of the more useful kinds of research that was pioneered in zoos has proved to be the association of juvenile patterns with those of adults, the demonstration that an adult with pattern A really produced clutches of juveniles with pattern $B$. I would like to suggest that it is necessary to supplement published descriptions and photographs of such series with the deposit of properly preserved juveniles. The deposit should perhaps consist of one or two of the animals preserved at birth, another pair preserved after one month, after three months, six months, etc. This would supplement photographic records of changes in colour patterns and proportion, and provide us with a block of material presently unavailable for most species. It is, of course, obvious for the benefit of furure studies that the specimens thus preserved should be more or less randomly sampled from the initial clutch; if only those that seem to be doing 'poorly' are preserved, a subsequent investigator may obtain a very biased view of changes with growth. We know almost nothing of the descriptive embryology of many species, even though studies on the development of organs are critical for understanding of their affunities and adaptations.

This recommendation that some members of each clutch should immediately be preserved is likely to raise the hackles of certain curators. However, we all know that many reptiles produce relatively large numbers of young, and the average zoological park may have some difficulty in arranging for the individual feeding, housing, and other procedures that will assure the survival of a significant fraction of these. Some specimens are given or traded to other exhibitors; however, in many more cases there is an inevitable attrition, perhaps reflecting properties of the individuals, but as likely reflecting an overload on the curatorial staff. When a captive population produces extra specimens, it is useful to tithe the offspring for such developmental studies. When breeding programmes are planned for endangered species, the deposit of juveniles should be written in as part of the initial project proposal.

It is, of course, possible to use the "kinds of studies we do here' as part of the exhibit programme. Unfortunately, many of the most useful things that are studied in laboratories are initially too tentative to be explained to anyone but a specialist without risking major errors. There may be an initial hope for long-range significance, but such significance can only be confirmed much later. Consequently, initial selection of a project on criteria, such as suitability of 'results' for exhibit, is unlikely to increase our long-range understanding and capacity to conserve organisms.

What does a particular zoo obtain in return for thus participating in the scientific enterprise, or what may the zoo demand in return for cooperating with its own scientists or those from other institutions? It is an obvious courtesy that anyone, who obtains aid in carrying out work, acknowledges the assistance when the project results in publication and makes copies of such publications available to all concerned. When particular members of the staffs of zoos have had a major share in the planning or execution of a project, it also seems appropriate that they share authorship of (and sometimes blame for) the resulting report. Research collaborators should be prepared to render other appropriate aid when necessary. Such aid may involve the provision of or reference to literature needed for other projects and information regarding disease states or similar topics of obscure species, perhaps those being exhibited for the first time. They should, furthermore, be prepared to assist the staff of co-operating 
zoos in designing and evaluating projects and exhibits and, where necessary, putting them into contact with specialists whose background is more pertinent to the affair than that locally available.

When a research project, particularly one being carried out for the interest of someone not directly associated with the zoo, demands the procurement of additional animals, it may be reasonable to have an outside source pay part or all of the cost. At the least, it should assure replacement of exhibit stock if the proceedings result in its damage or loss.

Actually the question of return for participation is probably posed in the wrong way. Ultimately, all those involved in interaction with wild animals, as part of nature parks management, exhibition in zoological gardens, museum establishment, and university research, have a common obligation in contributing to our fund of knowledge and in thus assuring the maintenance of wild populations. Zoos must take a critical role, both in obtaining new information and in disseminating it to other professionals and to their visitors from the public at large.

\section{ISSUES OF LIFE AND DEATH}

There is one final issue that I would like to address, even though doing so may transcend my mandate. I choose to do so because, to $m e$, it is fundamental to any consideration of the ethics of exhibition and research and because it tends to be dreadfully muddled when the nature of animals and of environments is presented in the popular press, in films and television. I am, of course, referring to the question of whether animals may be killed, why and when? This issue needs facing squarely as it reflects on many other aspects of our interactions with wild organisms. I was reminded that I should address it here because my recent plea for the avoidance of duplication in research on the part of game departments and those associated with the hide industry was reprinted in a conservation magazine under the unauthorised heading of 'Must Scientists Kill to Study'.

Such statements represent a most simplistic thinking about the life and death of organisms and about man's role in encompassing it. It confuses the death of individuals with the death of populations or of species. This is a critical difference that should be made clear, not only to any professional naturalist but also to any citizen sincerely concerned with the conservation of wild life. It may be sad but it is true that the existence of any organism on this world implies that it will utilise certain resources and, with this, make life difficult or impossible for some individuals of other species. Elephants probably kill some trees and bushes, and any individual herbivore is likely to destroy individual plants. Carnivores obviously kill their prey, whether we are dealing with polar bears that feed on seals or with snakes that catch centipedes.

Similarly, every activity, indeed the very existence of man, involves the use of resources that could support other organisms. Ploughing a field for the production of crops that will be consumed by vegetarians will often kill or displace deer, rabbit, and mice and will cortainly destroy many invertebrates. The harvesting of wild fruits and seeds adversely affects the fitness of those individual animals that might otherwise have been able to use this resource for the production of additional offspring of their own species. The construction of any house or other shelter, indeed any human activity, will inevitably have a deleterious effect on some of our fellow organisms.

Generally, such interactions among species do not lead to the extinction of the plants or the seals, the worms or the centipedes. Indeed, we notice that, in most cases, only a small fraction of the individual members of a wild population is likely to contribute offspring to the next generation. After all, a pair of toads could produce some thousands of offspring during their years of active mating, while a pair of garter snakes might produce so young per year. Other forms, such as halibut, supposedly exceed this capacity by a hundred times. Unless predation occurred, such forms would very soon exceed the resources available to them. This means not only that there are always some individuals dying or being killed from among a natural population, but that the fraction they comprise is generally so great in relation to the total population that the cropping of a specified number of individuals or the removal of a share of available resources need not immediately have a negative effect on the total population.

Unfortunately, man is likely to have a different and far more deleterious effect on many organ- 
isms, and I have already mentioned some ways in which this comes about. Every time we plough under an entire savanna, every time we drain large marshlands, every time we replace a native forest with pine, teak or eucalyptus, we have not only killed millions of individual animals and plants, but we are likely to have destroyed the conditions under which certain species could exist and have allowed them to become extinct. That is death in biological terms, and it is irreversible. Reducing a forest to a size too small for the local species of animals to find food, mates or nesting sites means dooming the population of animals just as surely as blasting away their nembers one by one with an elephant gun. The doom may arise in other ways as well; thus, the introduction of new predators or of competitors can destroy a native form. Sometimes the critical factor is the indirect end result of changes imposed on quite different species.

What can be done to arrest and reverse this process? First, we must know what are the critical factors for the survival of a particular species in a biotope; it may be a kind of food, a kind of shelter, or a social condition. Unfortunately the parameters involved are not absolute. There is no absolute number of food organisms that has to be retained to permit the survival of all carnivores. There is no minimum number of plant species that will guarantee the survival of every herbivore. There is no standard number of square kilometres of a particular kind of forest or grassland that will assure that diversity will be preserved. Such parameters differ for each species we are trying to protect and for changes in local conditions. Consequently, the process of conservation has to start with the process of study. We need to know which aspects of the environment are indeed critical for survival.

We must emphasise that environments, not just the individual species, have to be protected. We must save not only the tigers, elephants and giant tortoises of the world, but also its smaller creatures. Such smaller creatures should be protected, not because they are of interest to herpetologists and entomologists but because they are likely to have a critical effect on the stability of the environments within which the more spectacular organisms survive. We share this earth with some two million kinds of organisms. A realistic assessment of the problems in protecting a significant number thereof, quickly shows that a piecemeal approach is impractical. We cannot continue the process of developing lion reserves, zebra reserves and rhino reserves, much less Houston toad reserves, and Plains garter snake reserves. Noah's ark with multiple rooms, each housing 'a pair' of organisms, represents an impractical model for a successful attempt at conservation. The survival of most species can only be assured if we remove from intensive use by man at least part of regions that still contain samples of diverse biota. We must be able to defend decisions regarding the site and size of each park. Such justifications will only be convincing when they are based upon data derived from intensive study and analysis; when they represent guesses they may well be counterproductive.

Thus, it makes little sense to reserve an area for purposes of 'conservation' without understanding the area and its organisms and ecological associations. Unless we know something about the anatomy, physiology, and behaviour of a particular organism, i.e. about its natural history, we cannot select an area for the purpose of 'conservation', as we will not know that it is indeed suitable. Once a reserve is selected, its management must begin by obtaining a primary record of the kinds and numbers of organisms as well as of the ccological associations occupying it; this census must be repeated at regular intervals. How else could we know that change might be taking place? Change may be drastic but it may also be gradual. It may affect the numbers in a population, but it may also affect the genetics or health status of the population. Any census must take these aspects into account. There are other aspects of organisms that cannot immediately be determined by such a field survey; thus we require terrarium and laboratory studies on many levels.

A census and most biological study do involve the killing of some individual members of a species. These are cropped with the aim of ensuring the survival of the species as a whole. All phases of such study are designed to increase our understanding of the roles and demands of organisms in natural conditions. In planning such study, we must look broadly. Every succeeding decade discloses new factors that are critical to our understanding of animal biology. Conservation requires knowledge of biochemistry as 
well as of behaviour, of physiology as well as of ecology. Inevitably, co-existence requires that man must limit his expansion, but also that animal populations be studied, be exhibited, and perhaps be used.

Controlled sampling for study will hardly have a negative effect on the survival of the species being studied. Indeed, it will identify species that may be already on the edge of extinction for other reasons. In the case of forms that may have commercial potential, or that might be required in biomedical research, it can also provide information about the capacity of the population to withstand cropping and about ways in which such cropping may proceed with minimal stress on the individual organisms. Whether exploitation is actually carried out is presumably a social question, beyond the realm of science.

What each zoo can do, indeed what all zoos must do, is to point out to the public that zoos must participate in the study of organisms, and that study may demand some killing of individual specimens. Zoos must emphasise that study is required to provide the basis of saving species rather than serving to destroy them, and must stress that we still lack sufficient information to make reasonable assessments of the minimal conditions required for the survival of the vast majority of organisms. The message must be that a thorough understanding of the requirements of a species is the only way that the 'success' of a conservation effort may be assessed. Without it, one risks 'protecting' a district that may be deteriorating gradually without obvious indicators that could serve as a warning before the process has become irreversible.

The need for some 'killing' has to be understood by the staff of zoos, as well as by the public. As long as some professionals are unclear about the issues, they cannot complain about the attitude of the visitors. Cats kill and feed on rats and mice; indeed, this used to be their major utility to man. Snakes also feed on rats and mice; reports from Calcutta suggest that up to $50 \%$ of the stored cereals, in the absence of natural predators such as snakes, are destroyed by local rats. Yet there are places where the feeding of living rats to snakes is considered cruel, though the snake deals with the rat more quickly than would a keeper, and cats are not known to practice a 'clean kill'. It might not be appropriate to let small children watch feeding sessions before the children are also exposed to sex and birth among animals, but that is a decision for educators, and beyond the confines of herpetology.

The issue, whether or not living rodents are exposed to the 'hypnotic' eye of a living snake, may seem trivial, but it is important because of the implication that animals should not be killed. Man presumably intends to retain the claim to a significant share of the earth's resources. It is preposterous to plan for making the world safe for tsetse flies or malarial mosquitoes, of returning all of Wyoming to the buffalo or all of Ireland to the elk. A miniscule fraction of the world's human population is truly vegetarian, shunning eggs and fish, cheese and milk, but even vegetarians have to plough land (or have it done for them), and thus displace and kill other creatures. Most of my readers find it desirable, indeed ultimately profitable, to set aside certain resources to assure the survival of at least major groupings of animal species on this globe. Most of us will be willing to support such conservation efforts, even though they involve cost and deprivation at the moment. However, absolute protection of all individual animals can only be achieved by the mass suicide of man. Zoos must face and communicate the idea that decisions about conservation involve costs and that their implementation can only proceed on the basis of a sequence of studies that will cause some individual members of species to die.

\section{CONCLUSION}

It must be obvious that I sce zoological exhibits as an important aspect of the conservation of the world's biota. I hope that this discussion of seemingly discrete items has communicated my conviction of the unity of those biological endeavours involved in the process of conservation. Man will obviously continue to occupy a place on this globe and will utilise part of the available resources. However, it would probably be immoral, in the view of many of us, and quite clearly catastrophic in terms of future needs for viewing (and utilising) animal diversity, if we were not now to bend much of our energy toward the protection of the world's biota. While this clearly demands the setting up and protection of natural reserves, 
the success of the process also demands the co-operative interaction of other institutions. Thus, we need museums for maintaining reference collections of past and present organisms, laboratories for letting us ask those kinds of questions about behaviour and physiology that arc difficult or impossible when posed in other settings, and zoological parks for educating the public by cxhibiting specimens of native and exotic species, by selective propagation and by research on wild species.

Conservation also requires the efforts of a community of scholars, who can generate the basic information needed as the basis for informed decisions, and a community of specialists in the protection and management of wildlife, who will presumably utilise this information to deal with the practical issues of parks and reserves. Conservation also requires specialists who can converse with the public through the media of museum and zoo exlibits, and further specialists who will be able to maintain captive animals in good physical and psychological health. Ultimately, conservation requires an informed public that is willing to allocate an appropriate share of its resources in support of this set of tasks.

I have tricd to indicate that, although the tasks of each of these groups and each of these institutions are distinct, there is presumably only a single goal; hence, the borders among the several units should not be drawn too sharply. Each group and institution may well specialise for a primary task; the subdivision is determined by logistics and may change with time. The ultimate aim must be the most effective expenditure of the finite funds that the public has provided, and that are intended for conservation. Such tasks as education, exhibition and research are inevitably intertwined. Cost effectiveness of efforts at conservation in the broadest sense ultimately demands that each set of specialists not only be cognizant of but be prepared to support more than one task.

Finally, I hope to have been able to demonstrate how these aspects bear upon the exhibition of reptiles. The primary task of zoological parks is exhibition, and the primary task of the reptile house is that of showing reptiles (and sometimes other ectotherms) in the most pleasant surroundings, thus communicating to the visitor a sense of their beauty and of their significance. With this, a reptile house can transmit the message that even such 'lowly' inhabitants are worth protecting. Communication of this set of ideas is obviously a primary task. The secondary educational task may well be that of convincing the public that predators have an important role in ecosystems (but not just as exterminators of 'pests') and that vegetarians differ only in degree, but not in kind, from carnivores. The third educational task of a reptile house is that of giving the visitor some indication of how little is actually known about most organisms, and why study is still needed, indeed imperative.

Whatever the relative cmphasis that may be placed on different aspects of such a programme must obviously be decided on the basis of the local availability of the requisite physical, natural and human resources. However, the task of understanding and preserving some fraction of the natural world is so vast that it needs and deserves the assistance and co-operation of every herpetologist, whether serving as a reptile keeper or an educator, as a professional curator or a museum scientist, as a hobbyist or a parks employee.

ACKNOWLEDGBMENTS

I thank J. P. Bacon, John Behler, J. Kevin Bowler, H. Greene, Hugh Quinn, George Zug and Pat Zug for comments on this manuscript preparation of which was aided by NSF DEB 77-02605.

\section{REFERENCES}

BENNETT, A. F. \& NAGY, K. A. (1977): Energy expenditure in free-ranging lizards. Erology 58: 697-700.

BOGERT, C. M. \& COWLES, R. B. (1944): A preliminary study of the thermal requirements of desert reptiles. Bull. Am. Mus. nat. Hist. 83: 261-296.

BURGHARDT, G. M. (1978): Learning processes in reptiles, In Biology of the Reptilia 7(7). Gans, C. \& Tinkle, D. W. (Eds). London: Academic Press.

CARPENTER, c. c. (1978): Variation and evolution of stereotyped behavior in reptiles: survey. In Biology of the Reptilia 7 (6A). Gans, C. \& Tinkle, D. W. (Eds). London: Academic Press.

FOX, H. (1977): The urinogenital system of reptiles. In Biology of the Reptilia. 6 (I): Gans, C. \& Parsons, T. S. (Eds). London: Academic Press.

GANs, C. \& DAWSON, W. R. (Eds) (I976): Biology of the Reptilia 5 Physiology A. London: Academic Press.

GANS, C. \& VAN DEN SANDE, A. P. (1976): The exhibition of reptiles: concepts and possibilities. Acta zool, path. antwerp. 66: 3-SI. 
HUEY, R. B. \& SLATKIN, M. (1976): Costs and benefits of lizard thermoregulation. Q. Rev. Biol. $51: 363-38 \mathrm{r}$. RAND, A. S. (1964): Inverse relationship between temperature and shyness in the lizard Anolis lineatopus. Ecolog 4 45: 863-864.
TINkLE, D. W. \& GibBons, J. W. (r977): The distribution and evolution of viviparity in reptiles. Misc. Publs Mus. zool. Univ. Mich. 154: 1-55.

Manuscript submitted 20 March 1978

\title{
Marking amphibians and reptiles for future identification
}

\author{
RENÉ E. HONEGGER \\ Curator of Herpetology, Zoologischer Garten Zürich, CH-8044 Zürich, Switzerland
}

Wherever zoo animals are kept together in groups containing several members of the one species, and their progress followed over a continuous period of time, the need will inevitably arise to establish a system of individual identification that will be both accurate and permanent and that will serve as a valid foundation for the kind of scientific records that a modern zoo requires for its present and future reference (see, for example, Bowler, I977). The problem is now more pertinent than ever. With the increasing size of collections and changing habits of work, animal keepers are no longer in constant attendance on their charges. Once this intimate contact has been lost, the chances of their making a positive identification on the basis of some unique external feature or behaviour are correspondingly diminished. Some form of marking or other permanent source of identification that does not rely solely on personal observation and memory becomes a requisite.

Marking of birds and mammals is a relatively long-established practice which has carried over into the area of zoo husbandry the techniques leg-banding and branding or ear-tagging already in use in ornothological field studies and in the management of farm animals. Its application to amphibians and reptiles is a fairly recent development which began with the marking of wild-living specimens for behavioural studies (e.g. Breder et al., 1927; Jungfer, 1943; Bogert, 1947; Martof, I953; Dely, 1954; Heusser, I958).

Owing to their special anatomy and skin physiology, the permanent marking of amphibians and reptiles poses many difficulties which, perhaps with the exception of the Chelonia and
Crocodilia, have yet to be satisfactorily resolved. Amphibians in particular are notoriously difficult to mark. Frequent sloughing inhibits any techniques involving paint, as it does any other simple mechanical methods. In some taxa regeneration invites additional problems.

In recent years a growing interest in the subject amongst herpetologists and ecologists has resulted in a variety of ideas and experimentation involving the marking of amphibians and reptiles in the field. Many of the techniques which are listed in Tables I and 2 were laboratory tested over a relatively short period, or were intended to last for only a brief season of observation. To be acceptable for use on zoo animals, a system of identification must satisfy the following criteria. It must:

I. be as free as possible of pain and stress to the animal;

2. afford minimal opportunity for infection of the marked area;

3. not inhibit normal activities such as sloughing, courtship and mating, and feeding;

4. give no cause for negative criticism from public and zoo employees;

5 . be read with ease and from a distance;

6 . be adaptable to animals of all sizes;

7. be easy to use;

8 . be permanent.

On these criteria there is, in fact, only a limited selection of methods that can be recommended for permanent use in zoos. The Hungarian herpetologist Dely (I954), for example, used bird bands on the frogs Rana esculenta and Bombina bombina, which resulted within a short time in swelling of fore- and hind legs and, in one 